\title{
Looking for a Job, Finding the Right Employee
}

\author{
A.S. Leaflet R2169 \\ James Kliebenstein, Professor, Iowa State University, \\ Terrance Hurley, Associate Professor, University of \\ Minnesota, \\ Peter Orazem, Professor, Iowa State University, \\ Dale Miller, editor, National Hog Farmer, and \\ Steve May, publisher, National Hog Farmer

\section{Summary and Implications}

A survey of pig producers and employees was conducted to document trends in the industry. These surveys have been conducted four times: 1990, 1995, 2000, and 2005. Producers use a number of methods to locate employees and employees likewise use a number of methods to locate employment opportunities. The information job search networks are the dominant strategy used by producer and employees alike. Nearly half of the producers indicated they used word-of-mouth to find employees. About three in five employees also rely on word of mouth. Other methods used most frequently are newspapers, magazines and family referrals. Professional and college placement services were used more commonly by employees than producers. The time it takes, on average, to find an employee was 2.8 weeks in 2005, a reduction from 4.4 weeks a decade earlier (1995).

Producers face the challenge of matching labor needs with the available labor supply. For some needs, labor supply is plentiful and easy to access. Workers can be hired by the day or month. However, as skills become more specialized, the pool of qualified workers becomes scarce. To maintain a consistent supply of quality workers, the producer must invest in training and compensation packages that encourage workers to acquire needed skills, stay with the farm once trained, and remain motivated to work to improve farm profitability.

When labor is available only on a full-time basis, the addition or loss of an employee can have a sizable impact on the operation's labor supply. For some operations, the labor force can be cut in half or doubled by simply adding or releasing one employee. A producer who ignores employee management issues impacts the operation because worker turnover can severely impair the farm's productivity.

Employees in smaller operations may require more general skills because their responsibilities are likely to be more diverse from day-to-day. Employees in larger operations will likely have more specialized skills and a more narrow set of responsibilities.

\section{Introduction}

The pig production industry is experiencing changes in employment trends. As firms grow the need for employees grows as well. To document some of the changes a survey was conducted in late 2004 (2005 survey) of pig production employees and employers. This is the fourth survey in a 15 year span. The goal of the survey was to track changes in the employment market for pig production. Results of the 2005 survey are compared to the previous three surveys conducted in five year intervals $(2000,1995$, and 1990). This report documents methods used by producers in finding employees and by employees in finding jobs. Information on technology in use and part-time employment is also provided.

Getting potential employees and employers together can be a challenge. To better understand how producers locate employee prospects and how employees find job opportunities, both were asked how they approach their search.

\section{Materials and Methods}

As indicated, this was the fourth survey in a 15 year span. A mail questionnaire was sent to pork producers and employees across the United States. Select questions in both surveys overlapped so that responses could be compared in key areas.

The National Hog Farmer qualified mailing list provided a select sample of producers/owners. A random sample of producers with an annual production of 3,000 head or more, or verified with 100 sows or more, were surveyed. All employees on the National Hog Farmer list were sent the survey.

\section{Results and Discussion}

Informal job search networks are a dominant search strategy for both employers and workers (Table 1). By far the most common method of finding employees for producers is word-of-mouth with nearly half relying on this source. About three in five employees also rely on word-of-mouth, which makes it their most common source of job leads. The importance of these informal job search networks has remained strong over the past decade. Newspapers and family referrals are the next most common strategy used by producers. While employees also relied heavily on newspapers, they used magazines slightly more often than family referrals in 2000 and 2005. It is also interesting to note that almost one in 
three employees use magazines but about one in ten producers do.

Professional and college placement services are used more commonly by employees than producers. Alternatively, with the exception of 1995, producers have relied on vocational placement services more than employees. In 2005, producers used vocational placement services more often than they used professional and college placement services. The reverse was true for employees. The increased importance of vocational placement services for producers reflects a ten year trend. Alternatively, the use of professional placement services has been cyclical - relatively high in 1990 and 2000, but relatively low in 1995 and 2005. The internet is a popular strategy noted by one in five employees in 2005. However, about one in twenty producers relied on the internet to solicit job applicants.

In the past, employees have used a broader search strategy than producers by using more sources to locate job openings. This trend continued in 2005.

A producer's success at generating job applicants rebounded from 2000, but was still less than the high in 1995 (Table 2). Unfortunately, the increase in the number of qualified applicants reported in 2005 did not rebound with the number of applicants. Furthermore, the amount of time required to fill the last full-time opening actually increased slightly when compared to 2000 . However, the 2.8 week average needed to find an employee in 2005 still represents a substantial improvement over the 4.4 week average reported a decade ago. Also on a positive note, producers reported they were able to fill their last part-time opening faster than in the past.

Relating alternative search strategies to the number of job applications a producer received and the weeks required to fill a full-time position provides several interesting insights. First, producers who used the newspaper to search for new employees received more applications and more qualified applications on average, which helps explain the popularity of the strategy. Producers who used college placement services also generated more than the average number of qualified applicants, while decreasing the proportion of unqualified applicants. Word-of-mouth improved the average number of qualified applicants, while decreasing the number of unqualified applicants. However, it also increased the average weeks needed to fill an opening.

\section{New Technology}

Pork production is a biologically constrained process. Stock must be bred, followed by a fixed gestation period, farrowing, weaning, growing, and finishing. In some places, technology can speed or improve the process. Artificial insemination can help improve gene pools and extend the use of the best genetics. Early weaning may reduce a sow's rebreeding time. Split-sex and phase feeding can target nutritional programs and improve feed efficiency. All-in/all-out (AIAO) and multi-site production can help curb the spread of disease and reduce death loss. Each of these technologies improves efficiency by either speeding up the production cycle, lowering input cost and/or reducing output loss. In addition to production technologies, streamlined organization and management can help allocate resources more efficiently. For example, computers can reduce the time required and improve the accuracy of maintaining production and financial records. Formal employee management practices such as the provision of employee handbooks, written job descriptions, work plans and formal evaluation procedures can help efficiently organize and direct labor resources.

The adoption of a new technology follows a predictable pattern. Initially the adoption rate is slow, as only the most entrepreneurial firms are willing to explore the technology's potential. As the benefits of a new technology become clear, more and more firms start to follow. The adoption rate accelerates. Eventually, adoption reaches a peak because firms that find the technology beneficial use it, while those that do not find it beneficial do not use it. In some instances, the level of adoption of a new technology may even begin to decline as newer and better technologies begin to replace it.

Most of the technologies tracked by the survey over the past decade have moved into the final stages of the technology adoption cycle (Table 3 ). With the exception of formal management practices, the percentage of producers reporting the use of various technologies declined between 2000 and 2005. For split-sex feeding and phase feeding, the decline was substantial. There was also a substantial decline in the percentage of employees that reported split-sex feeding. The percentage of employees reporting phase feeding, multi-site production, and AIAO declined, while reports of artificial insemination, segregated early weaning, and formal management practices increased.

Two new technologies that emerged over the past fives years and appear to be moving towards the accelerated phase of the adoption cycle are autosorting and parity based management. About 1 in 20 producers and employees reported auto-sorting, a practice that houses finishing hogs together in large pens and uses scales to separate hogs that have reached market weight. The benefits of the technology include reduced labor costs for marketing hogs, improved animal welfare, and improved fed efficiency. Just over 1 in 10 producers and 1 in 4 
employees reported the use of parity based management. The practice segregates gilts and sows based on parity. Benefits of the practice include better conception rates, better nutrition, and lower culling rates. More in depth analysis helped reveal important characteristics of the types of operations using different technologies.

Larger operations are using more technology. With the exception of artificial insemination, the technology adoption increased with annual hog production. Operations with more employees are more likely to be using artificial insemination, multisite production, parity based management and formal management practices. Older producers are less likely to use artificial insemination and phase feeding. Alternatively, more educated producers are more likely to use phase feeding, parity based management, and formal management.

Regionally, phase feeding is most popular in the Midwest. Split-sex feeding, multi-site production, segregated early weaning, and AIAO are not used as often on average by Southeastern operations. Formal management practices are used more often than average in the West, but multi-site production in not used as commonly as in the Midwest or Northeast.

The adoption of personal computers (PC) leveled off in 2005, with about 2 in 3 producers and 3 in 4 employees reporting their use (Table 4). Financial record keeping is the more common use for PCs reported by producers, while production record keeping is the more common use reported by employees. Indeed, over the last decade the number of employees working for operations that use PCs for production record keeping increased by $15.4 \%$. Employee training on PCs increased by $57.8 \%$ during this time. More-educated producers and employees and those on larger operations were significantly more likely to report the use of a PC. Older producers and producers in the Southeast were the least likely to use PCs.

Some technological advances require few if any special skills to implement. For example, multiplesite production requires little if any additional skill on the part of labor. But, alternatively, PC use or introducing artificial insemination requires special training. If new technologies require employees to have special skills, then they may command higher compensation for acquiring or being blessed with these special skills. Using statistical comparisons, it is possible to calculate how much more an employee earns by being able to work with new technologies. When making these statistical comparisons, the only difference between the two employees is the difference in the technologies adopted by their employers. Table 5 shows these statistical comparisons for the earnings of employees working in an operation with and without a specific technology.

For example, an employee working for an operation that uses AI earned $7.4 \%$ more on average in 1995 than an identical worker on a farm that did not use AI. By 2005, the wage premium associated with AI use rose to $22.2 \%$. This result suggests that operations that use AI require special skills that are more valuable to producers. In contrast, wage differentials associated with split-sex feeding and multi-site production are very small and even negative in some instances. For example, the analysis suggests an employee on a farm using multi-site production earned only a $0.5 \%$ wage premium in 1995 and actually earned $1.5 \%$ less in 2005 when compared an identical worker in a single-site operation. Apparently, employees need few, if any, special skills in order to work for operations that use multiple sites, split-sex feeding, auto-sorting, or parity based management.

AI, phase feeding, AIAO production, formal management and $\mathrm{PC}$ use all seem to require special employee skills. To attract and retain those skills, employers have to pay a wage premium.

Consequently, employees working for these operations enjoy higher wages on average. Notice that wage premiums paid for PC skills declined between 1995 and 2005, which indicates these skills are becoming commonplace in the labor force.

\section{Part-Time Employment}

The average number of part-time employees fell by nearly a third, while the proportion of operations using part-time help increased slightly between 2000 and 2005 (Table 6). The hours of weekly work expected from these employees has continued the 15 year downward trend. Alternatively, the going wage for part time labor has continued to trend upward, with more than half the producers now offering wages in excess of $\$ 8$ an hour rate. The proportion of operations offering part-time wages in excess of $\$ 10$ an hour also more than doubled from 6.6 to $15.5 \%$ between 2000 and 2005 .

\section{Acknowledgements}

Appreciation is expressed to the National Pork Board for providing funding for the study. 
Table 1: Methods Used to Locate Job Applicants by Producers and Job Openings by Employees.

Producer

\begin{tabular}{lcccccccc} 
& $\mathbf{2 0 0 5}$ & $\mathbf{2 0 0 0}$ & $\mathbf{1 9 9 5}$ & $\mathbf{1 9 9 0}$ & $\mathbf{2 0 0 5}$ & $\mathbf{2 0 0 0}$ & $\mathbf{1 9 9 5}$ & $\mathbf{1 9 9 0}$ \\
\hline \hline & \multicolumn{9}{c}{ Percent } \\
College or Vocational & 13.5 & 14.7 & 12.8 & 20.8 & 24.7 & 25.0 & 27.6 & 29.5 \\
Placement Service & 7.8 & 9.6 & 8.3 & NA & 20.7 & 21.6 & 23.4 & NA \\
College Placement Service & 9.5 & 9.1 & 7.7 & NA & 9.4 & 8.4 & 9.6 & NA \\
Vocational Placement Service & 6.5 & 9.8 & 6.3 & 10.4 & 15.8 & 22.0 & 17.3 & 19.2 \\
Professional Placement Service & 27.1 & 27.3 & 21.5 & 27.7 & 52.7 & 57.4 & 47.7 & 40.7 \\
Magazine or Newspaper & 7.7 & 6.2 & 4.8 & NA & 29.6 & 29.0 & 24.8 & NA \\
Magazine & 25.4 & 26.0 & 20.6 & NA & 45.1 & 50.2 & 41.9 & NA \\
Newspaper & 47.2 & 47.3 & 44.6 & NA & 61.0 & 68.2 & 63.7 & NA \\
Word of Mouth & 25.2 & 24.3 & 21.3 & NA & 27.7 & 27.0 & 28.2 & NA \\
Family & 3.4 & NA & NA & NA & 21.4 & NA & NA & NA \\
Internet & 5.4 & 4.9 & 5.5 & NA & 5.8 & 7.1 & 7.7 & NA \\
Other &
\end{tabular}

Note: NA means this response was not offered.

Table 2: Success of Producer's Search for New Employees.

\begin{tabular}{lcccc} 
Application/Open Position & $\mathbf{2 0 0 5}$ & $\mathbf{2 0 0 0}$ & $\mathbf{1 9 9 5}$ & $\mathbf{1 9 9 0}$ \\
\hline \hline & 4.0 & 3.2 & 5.1 & 2.8 \\
Applications Received & 1.3 & 1.3 & 1.7 & 0.8 \\
Qualified Applications Received & 2.8 & 2.7 & 4.4 & 1.7 \\
Weeks Needed to Fill Last Full-Time Opening & 1.5 & 2.1 & 2.8 & 3.0 \\
Weeks Needed to Fill Last Part-Time Opening & \multicolumn{4}{c}{ Average } \\
\hline \hline
\end{tabular}

Table 3: Technology Use.

\begin{tabular}{lcccccc} 
& \multicolumn{3}{c}{ Producers } & \multicolumn{3}{c}{ Employees } \\
\cline { 2 - 7 } & $\mathbf{2 0 0 5}$ & $\mathbf{2 0 0 0}$ & $\mathbf{1 9 9 5}$ & $\mathbf{2 0 0 5}$ & $\mathbf{2 0 0 0}$ & $\mathbf{1 9 9 5}$ \\
\hline \hline Production Technology & & Percent & & & Percent \\
Artificial Insemination & 47.1 & 48.2 & 30.7 & 76.7 & 76.4 & 56.2 \\
Split-Sex Feeding & 36.6 & 46.0 & 40.7 & 39.3 & 46.5 & 47.5 \\
Phase Feeding & 52.5 & 59.3 & 55.1 & 49.8 & 50.9 & 55.2 \\
Multi-Site Production & 32.1 & 34.6 & 28.4 & 45.9 & 47.0 & 38.7 \\
$\quad$ Segregated Early Weaning & 30.2 & 32.5 & 12.2 & 31.8 & 28.8 & 14.7 \\
$\quad$ All-In/All-Out & 66.7 & 68.1 & 58.5 & 60.6 & 64.7 & 67.3 \\
$\quad$ Auto-Sorting & 5.4 & NA & NA & 5.9 & NA & NA \\
$\quad$ Parity Based Management & 10.8 & NA & NA & 26.1 & NA & NA \\
Management Technology & & & & & & \\
$\quad$ Formal Management Practices & & & & & & \\
\end{tabular}

Note: NA means this response was not offered.

${ }^{a}$ Formal management practices reflect and employer's use of employee handbooks, job descriptions, written work plans, and formal evaluation procedures. 
Table 4: Personal Computer Use.

Producers

\begin{tabular}{lcccccccc} 
& $\mathbf{2 0 0 5}$ & $\mathbf{2 0 0 0}$ & $\mathbf{1 9 9 5}$ & $\mathbf{1 9 9 0}$ & $\mathbf{2 0 0 5}$ & $\mathbf{2 0 0 0}$ & $\mathbf{1 9 9 5}$ & $\mathbf{1 9 9 0}$ \\
\hline \hline & \multicolumn{9}{c}{ Percent } & \multicolumn{7}{c}{ Percent } \\
Use Personal Computer & 62.2 & 69.4 & 57.3 & 40.8 & 74.5 & 74.0 & 69.9 & 46.2 \\
Use for Production Record Keeping & 51.9 & 60.2 & 50.2 & NA & 77.8 & 71.8 & 67.4 & NA \\
Use for Financial Record Keeping & 68.1 & 73.1 & 61.9 & NA & 68.3 & 68.4 & 66.1 & NA \\
Trained to Use & NA & 59.1 & 48.1 & 35.3 & 72.3 & 51.4 & 45.8 & 34.0 \\
\hline \hline
\end{tabular}

Note: NA means this response was not offered.

Table 5: Differences in Wages by Selected Differences in Technology Use.

\begin{tabular}{lccc} 
& & Difference in Wages \\
Difference in Technology Use & $\mathbf{2 0 0 5}$ & $\mathbf{2 0 0 0}$ & $\mathbf{1 9 9 5}$ \\
\hline \hline & & Percent & \\
Artificial Insemination vs No Artificial Insemination & 22.2 & 11.9 & 7.4 \\
Split Sex Feeding vs No Split Sex Feeding & -2.9 & 0.2 & 1.3 \\
Phase Feeding vs No Phase Feeding & 11.3 & 5.6 & 7.6 \\
Multi-Site Production vs No Multi-Site Production & -1.5 & -0.9 & 0.5 \\
Segregated Early Weaning vs No Segregated Early Weaning & 0.2 & 5.7 & 2.4 \\
All-In/All-Out Production vs No All-In/All-Out Production & 9.7 & 6.1 & 7.0 \\
Auto Sorting vs No Auto Sorting & -4.8 & $\mathrm{NA}$ & $\mathrm{NA}$ \\
Parity Based Management vs No Parity Based Management & -10.0 & $\mathrm{NA}$ & $\mathrm{NA}$ \\
Formal Management vs No Formal Management & 5.1 & 7.5 & 14.7 \\
Personal Computer Use vs No Personal Computer Use & 2.3 & 4.2 & 5.5 \\
\hline \hline
\end{tabular}

Note: NA means this response was not offered.

Table 6: Part-Time Labor.

\begin{tabular}{|c|c|c|c|c|}
\hline & 2005 & 2000 & 1995 & 1990 \\
\hline Expected Part-Time Hours/Week & \multicolumn{4}{|c|}{ Percent } \\
\hline 10 or less & 43.3 & 35.0 & 32.0 & 34.0 \\
\hline $10-15$ & 15.5 & 18.0 & 18.8 & 17.3 \\
\hline $15-20$ & 19.4 & 21.2 & 21.3 & 20.2 \\
\hline $20-25$ & 12.7 & 13.1 & 15.2 & 16.0 \\
\hline $25-30$ & 6.4 & 7.5 & 6.8 & 5.4 \\
\hline 30 or more & 2.7 & 5.2 & 5.8 & 7.1 \\
\hline \multicolumn{5}{|l|}{ Part-Time Hourly Wages } \\
\hline$\$ 3-4$ & 1.2 & 2.2 & 2.8 & 13.3 \\
\hline$\$ 4-5$ & 2.2 & 1.9 & 15.1 & 40.3 \\
\hline$\$ 5-6$ & 6.2 & 19.0 & 35.5 & 34.5 \\
\hline$\$ 6-7$ & 16.4 & 27.2 & 27.4 & 8.1 \\
\hline$\$ 7-8$ & 18.9 & 23.1 & 12.6 & 2.6 \\
\hline More than $\$ 8$ & 55.1 & 26.5 & 6.6 & 1.2 \\
\hline$\$ 8-9$ & 17.6 & 9.8 & 3.0 & NA \\
\hline$\$ 9-10$ & 22.0 & 10.1 & 1.6 & NA \\
\hline More than $\$ 10$ & 15.5 & 6.6 & 2.0 & NA \\
\hline \multicolumn{5}{|l|}{ Producers Reporting Use of Part-Time } \\
\hline \multirow[t]{2}{*}{ Employees } & 45.1 & 44.5 & 44.5 & 47.4 \\
\hline & \multicolumn{4}{|c|}{ Average Number } \\
\hline Part-Time Employees & 2.1 & 3.4 & 1.6 & 1.6 \\
\hline
\end{tabular}

Note: NA means this response was not offered. 
Iowa State University does not discriminate on the basis of race, color, age, religion, national origin, sexual orientation, gender identity, sex, marital status, disability, or status as a U.S. veteran. Inquiries can be directed to the Director of Equal Opportunity and Diversity, 3680 Beardshear Hall, (515) 294 - 7612 . 